\title{
Estimating the Effects of Understory Removal From a Douglas Fir Forest Using a Two-Layer Canopy Evapotranspiration Model
}

\author{
F. M. KelliheR ${ }^{1}$ AND T. A. BlaCK \\ Department of Soil Science, University of British Columbia, Vancouver \\ D. T. PrICE \\ Faculty of Forestry, University of British Columbia, Vancouver
}

\begin{abstract}
W. J. Shuttleworth's (1979) development of the Penman-Monteith evaporation equation for multilayer, partially wet forest canopies was modified for application to the hypostomatous canopies of Douglas fir and salal. This theory was combined with standard hourly micrometeorological measurements, eddy diffusive, boundary layer and stomatal resistance functions, and canopy and root zone water balance equations to calculate evapotranspiration rates $(E)$ from a Douglas fir forest with salal understory over extended periods during two growing seasons. Calculated values of $E$ agreed to within $0.2 \mathrm{~mm} \mathrm{d^{-1 }}$ of values determined using Bowen ratio-energy balance measurements. The courses of average root zone volumetric water content $(\theta)$ calculated for two extended periods agreed well with neutron probe measurements. Salal understory removal resulted in measured values of $\theta$ being only $0.01-0.03 \mathrm{~m}^{3} \mathrm{~m}^{-3}$ higher over the two periods, in close agreement with calculations. This corresponded to calculated tree transpiration rates being $0.4 \mathrm{~mm} \mathrm{~d} \mathrm{~d}^{-1}$ higher on average, during the second half of both periods. These higher rates were confirmed by stomatal resistance measurements.
\end{abstract}

\section{INTRODUCTION}

The Penman-Monteith equation [Monteith, 1965] has provided useful insight into the physical and physiological factors affecting forest evapotranspiration [Stewart and Thom, 1973; Tan and Black, 1976]. A further development of the equation for multilayer, partially wet forest canopies has provided a practical one-dimensional model [Shuttleworth, 1978, 1979], despite the simplifying assumptions regarding within canopy turbulent transfer [Jarvis et al., 1976; Raupach and Thom, 1981; Finnegan, 1985]. With standard hourly micrometeorological measurements and stomatal resistance characteristics, the model can be combined with a root zone water balance model [e.g., Spittlehouse and Black, 1982] to provide estimates of forest evapotranspiration over extended periods. This paper (1) describes the evapotranspiration model as modified for use in hypostomatous canopies, (2) tests the model using energy and water balance measurements, and (3) uses the model to explain the effects of salal (Gaultheria shallon Pursh.) understory removal on tree transpiration rates in a Douglas fir (Pseudotsuga menziesii (Mirb.) Franco) forest.

THEORY

Using Shuttleworth's [1979] evapotranspiration theory, assuming the similarity of sensible heat and water vapor aerodynamic transfer resistances and neglecting canopy energy storage, it can be shown that the water vapour flux density from layer $i\left(E_{i}{ }^{\prime}\right)$ with leaf area (one side) index $\left(a_{i}\right)$ within a multilayer forest canopy of hypostomatous leaves can be expressed as (see the appendix)

$$
E_{i}^{\prime}=\frac{s\left(R_{n i}-G\right)+\rho c_{p}\left(D_{i}-\delta_{i}\right) / r_{A i}}{L\left[s+\gamma\left(1+r_{c i} / r_{A i}\right)\right]}
$$

${ }^{1}$ Now at Forest Research Institute, Private Bag, Rotorua, New Zealand.

Copyright 1986 by the American Geophysical Union.

Paper number 6W4433.

0043-1397/86/006W-4433\$05.00 where $E_{i}^{\prime}$ is the difference between the water vapor flux density above and below the layer (i.e., $E_{i}-E_{i-1}$ ); $R_{n i}$ and $D_{i}$ are the net radiation flux density and vapor pressure deficit above layer $i$, respectively; $G$ is the soil heat flux density; $L$ is the latent heat of vaporization; $\rho$ is the density of air; $c_{p}$ is specific heat of air; $s$ is the slope of the saturation vapour pressure curve; $\gamma$ is the psychrometric constant, and

$\delta_{i}=\left[s\left(R_{n i-1}-G\right)\left(r_{b i} /\left(2 a_{i}\right)\right)+(s+\gamma) L E_{i-1} r_{a i}\right] /\left(\rho c_{p}\right)$

The total aerodynamic resistance $\left(r_{A i}\right)$ [Thom, 1972] is given by

$$
r_{A i}=r_{a i}+r_{b i} /\left(2 a_{i}\right)
$$

and the canopy resistance of layer $i\left(r_{c t}\right)$ is expressed as

$$
\begin{array}{r}
r_{c i}=\left[\frac{W_{i}}{(1+s / \gamma) r_{b i} /\left(2 a_{i}\right)}+\frac{1-W_{i}}{r_{s i} / a_{i}+(2+s / \gamma) r_{b i} /\left(2 a_{\imath}\right)}\right]^{-1} \\
-(1+s / \gamma) r_{b i} /\left(2 a_{i}\right)
\end{array}
$$

where $r_{a i}$ is the eddy diffusive resistance above layer $i, r_{b i}$ and $r_{s i}$ are the boundary layer and stomatal resistances of one side of the leaves in layer $i$, respectively, and $W_{i}$ is the fraction of leaf area in layer $i$ that is completely wet. Stomatal resistances of hypostomatous leaves of Douglas fir and salal on a onesided basis have been related to light, leaf and soil water potential, and vapor pressure deficit [Tan et al., 1977, 1978].

Equation (1) is recognized as the Penman-Monteith equation with an additional term which accounts for the net radiation, latent and sensible heat flux densities below layer $i$. Black et al. [1970] used (1) as an evapotranspiration model for a dry snap bean canopy where $r_{b i} \ll r_{s i}$ was assumed so that $\delta_{i}$ was equal to the soil evaporation rate multiplied by $r_{a i}(s$ $+\gamma) /\left(\rho c_{p}\right)$. If $r_{a i}$ is assumed to be zero, then (1) reduces to the Penman-Monteith equation applied to the layer (i.e., using the vapor pressure deficit and the available energy flux density $\left(R_{n t}-R_{n i-1}\right)$ within the layer). Equation (4) gives the canopy 
resistance of a partially wet layer assuming that the individual leaves are either completely wet or completely dry so that the wet and dry leaves have different temperatures. Equation (4) differs slightly from Shuttleworth's [1978] (32) because his derivation was for amphistomatous leaves. When $W_{i}=0$, $r_{c i}=r_{s i} / a_{i}+r_{b i} /\left(2 a_{i}\right)$ compared to $r_{c i}=r_{s i} /\left(2 a_{i}\right)$ for an amphistomatous leaf canopy as in (24) of Shuttleworth. As expected, when $W_{i}=1, r_{c i}=0$ in both hypostomatous and amphistomatous cases. Making use of Shuttleworth's theory it can be shown that the rate of evaporation of intercepted water from layer $i\left(E_{I i}{ }^{\prime}\right)$ is given by (see the appendix)

$$
E_{l i}^{\prime}=\frac{E_{i}^{\prime} W_{i}\left[(2+s / \gamma) r_{b i}+2 r_{s i}\right]}{(1+s / \gamma) r_{b i}+W_{i}\left(r_{b i}+2 r_{s i}\right)}
$$

The vapor flux density above layer $i\left(E_{i}\right)$ is given by summing (1) from 0 to $i$, so that for a canopy of $n$ layers the evapotranspiration rate is

$$
E=\sum_{i=0}^{n} E_{i}^{\prime}
$$

where $E_{0}=E_{0}{ }^{\prime}$ is the evaporation rate from the forest floor with $\delta_{0}=O$ and $r_{c 0}$ being the forest floor diffusive resistance [Denmead, 1984; Shuttleworth and Wallace, 1985]. In this study the forest canopy was divided into two layers $(n=2)$, where the Douglas fir subcanopy was designated as layer 2 and the salal subcanopy as layer 1 .

\section{MeTHODS}

\section{Site Description}

The site was a 31-year-old Douglas fir stand with about 800 trees $\mathrm{ha}^{-1}$, approximately $27 \mathrm{~km}$ northwest of Courtenay on the eastern coast of Vancouver Island $\left(49^{\circ} 50^{\prime} \mathrm{N}, 125^{\circ} 14^{\prime} \mathrm{W}\right.$, $150 \mathrm{~m}$ above sea level). At the end of the 1982 growing season, stand (excluding understory) basal area was $16 \mathrm{~m}^{2} \mathrm{ha}^{-1}$, and average tree height was $14 \mathrm{~m}$. Average tree and salal understory leaf area indices on a one-sided leaf area basis, were about 6 and 3, respectively, in 1982. The soil, an Orthic Humo Ferric Podzol, is a gravelly sandy loam with a volumetric coarse fragment ( $>2 \mathrm{~mm}$ diameter) content of $10-45 \%$. It is covered with a layer of organic forest floor material $10-20 \mathrm{~mm}$ thick and is about $700 \mathrm{~mm}$ deep over sandstone bedrock. The site is on a slope of less than $10 \%$, with a northeast aspect.

The model was tested using stand energy balance measurements made in 1982 and soil water content and potential measurements made in 1981 and 1982 in four circular plots about $7 \mathrm{~m}$ in diameter, each containing two subplots, one with salal understory present and the other with it cut and removed on May 21, 1981. Each subplot contained one tree which was similar in size to the one in the adjacent subplot. The root zones of all eight trees were isolated by a vertical plastic barrier consisting of two sheets of 0.15 -mm-thick polyethylene extending down to bedrock [Kelliher, 1985; Price et al., 1986].

\section{Micrometeorological Measurements}

Routine measurements of solar irradiance above the stand, air temperature, and relative humidity in a Stevenson screen at the $6 \mathrm{~m}$ height, wind speed at the $15 \mathrm{~m}$ height, and precipitation above the stand were made throughout the 1981 and 1982 growing seasons. Data were recorded as one hour averages or totals using a data logger (model CR21, Campbell Scientific Inc., Logan, Utah).

In $1981, R_{n}$ above the forest $\left(R_{n g}\right)$ was measured using a model S-1 radiometer (Swissteco Pty. Ltd., Victoria, Australia), while $R_{n}$ below the tree canopy $\left(R_{n b}\right)$ was measured in one plot using one net radiometer above the salal canopy and another above the forest floor surface, where salal had been removed. In 1982, $R_{n a}$ was estimated, prior to August, from solar irradiance measurements following Gates [1980]. During August 1982, $R_{n a}$ was measured as in 1981, but $R_{n b}$ was measured using an S-1 net radiometer mounted on a tram traveling at the $1-\mathrm{m}$ height along a $10-\mathrm{m}$ path where salal along one half of the path had been removed [Kelliher, 1985]. The tram traveled at $0.5 \mathrm{~m} \mathrm{~min} \mathrm{~m}^{-1}$ and automatically reversed when it reached each end. The net radiometer output voltage was measured every $10 \mathrm{~s}$. These results showed that $R_{n b}$ was approximately $0.16 R_{n a}$ and $0.14 R_{m a}$ for uncut and cut subplots, respectively. In 1982 , these relationships were used to estimate $\boldsymbol{R}_{n b}$ prior to August. In both years, $\boldsymbol{R}_{n 0}$ below the salal canopy was estimated using $R_{n 0}=((s+\gamma) / s) L E_{0}+G$ where $L E_{0}$ was $2 \mathrm{~W} \mathrm{~m}^{-2}$ (measured using small lysimeters described later). The soil heat flux density at the 50-mm depth in each subplot of one plot was measured during 1981 and in August 1982 using three soil heat flux plates $(100 \mathrm{~mm}$ long $\times 25 \mathrm{~mm}$ wide $\times 3 \mathrm{~mm}$ thick), made following the design of Fuchs and Tanner [1968], connected in series and corrected for the rate of change of heat storage in the upper $50 \mathrm{~mm}$ of soil. On the basis of these measurements, $G$ was estimated as $0.02 R_{n a}$ and $0.03 R_{n a}$ for uncut and cut subplots, respectively, in 1982.

In both years, air temperature $\left(T_{\text {air }}\right)$ and vapor pressure deficit $(D)$ were estimated below the tree canopy using hourly average values at the $6-\mathrm{m}$ height with the relationships $T_{\text {air }}$ $\left({ }^{\circ} \mathrm{C}\right)(0.5 \mathrm{~m}$ height $)=0.93 T_{\text {air }}\left({ }^{\circ} \mathrm{C}\right)(6 \mathrm{~m}$ height $)+1.2$ and $D(\mathrm{kPa})(0.5 \mathrm{~m}$ height $)=0.89 \mathrm{D}(\mathrm{kPa}) \quad(6 \mathrm{~m}$ height $)-0.03$ (based on 33 hourly average measurements of $T_{\text {air }}$ and $D$ at both heights on July 24 and 25, 1981). Hourly Assmann psychrometer measurements confirmed the validity of these relationships on several days in August 1981 and June 1982.

\section{Diffusive Resistance Functions}

Stomatal resistances $\left(r_{s}\right)$ of Douglas fir and salal were estimated using average root zone soil water potential $\left(\Psi_{s}\right)$ and $D$ for the layer following interpolation of the functions in $T$ an et al. [1978] [Kelliher, 1985]. When $R_{n a}$ was negative (i.e., 19000700 hours PST), $r_{s}$ of both species was set to $10^{5} \mathrm{~s} \mathrm{~m}^{-1}$. Boundary layer resistances $\left(r_{b}\right)$ were estimated using a function for artificial leaves in the work by Spittlehouse and Black [1982] and a shelter factor of two [Landsberg and Powell, 1973; Jarvis et al., 1976]. The function $r_{b}\left(\mathrm{~s} \mathrm{~m}^{-1}\right)=2 \times 184$ $\left(d_{l} / u\right)^{0.5}$ was used, where $d_{l}$ is leaf diameter $(\mathrm{m})(0.001 \mathrm{~m}$ for Douglas fir and $0.06 \mathrm{~m}$ for salal) and $u$ is the wind speed (m $\left.\mathrm{s}^{-1}\right)$ near the leal $\left(0.5 u_{15 \mathrm{~m}}\right.$ for Douglas fir and $0.13 u_{15 \mathrm{~m}}$ for salal, where $u_{15 \mathrm{~m}}$ is the wind speed at the $15-\mathrm{m}$ height). In 1982 (prior to August), $u_{15 \mathrm{~m}}$ was estimated to be $3 \mathrm{~m} \mathrm{~s}^{-1}$ for 1100-2000 hours PST and $1.5 \mathrm{~m} \mathrm{~s}^{-1}$ for the rest of the day. Dividing these values by $2 a_{i}$ gave mean boundary layer resistances similar to those estimated following the relationships given by Garratt and Hicks [1973]. The eddy diffusive resistance above the Douglas fir layer, required when the air temperature and relative humidity measured at the $15-\mathrm{m}$ height in August 1982 were used, was estimated assuming a logarithmic wind profile [Jarvis et al., 1976] with a zero-plane displacement height of $8.5 \mathrm{~m}$ [Szeicz et al., 1969] and a roughness length of $1.5 \mathrm{~m}$ [Stanhill, 1969]. The corresponding resistance above the salal layer was roughly estimated assuming an ex- 
ponential eddy diffusivity profile from the top of the trees to the salal layer [Thom, 1975; Shuttleworth and Wallace, 1985] with an attenuation coefficient of 2 . This value was based on the ratio of the below to above tree canopy windspeeds being about 0.13. Daytime eddy diffusive resistances above the salal layer were calculated to be about $40 \mathrm{~s} \mathrm{~m}^{-1}$ compared to approximately $20 \mathrm{~s} \mathrm{~m}^{-1}$ for the 600 trees ha-1 Thetford [Shuttleworth, 1979; Roberts et al., 1980] and the 400 trees $\mathrm{ha}^{-1}$ Jadraas [Lindroth, 1984] forests. For the cut subplots, values of $r_{a i}$ estimated for the salal layer were used.

Forest floor diffusive resistances $\left(r_{c 0}\right)$ for 10 days in July and August 1981 were determined by choosing a value which resulted in agreement between daily total values of measured and calculated $E_{0}$ on each day. Measurements of $E_{0}$ were made in the cut subplot of plot 2 using plastic-walled lysimeters $150 \mathrm{~mm}$ in diameter and $120 \mathrm{~mm}$ deep, which were weighed every 1-2 hours. The undisturbed soil cores in the lysimeters were replaced every 1-2 days. The values of $r_{c 0}$ were related to average root zone water content (see Results and Discussion) for calculations of forest floor diffusive resistances on other days.

For each Douglas fir tree in a subplot, leaf area was estimated from the diameter at the $1.37-\mathrm{m}$ height using a function in the work by Spittlehouse [1981]. Ground area occupied by the tree was estimated using a tree location map and the "polygon of occupancy" [Santantonio et al., 1977]. Tree leaf area divided by the polygon of occupancy was taken as the value of leaf area index $(a)$ for each of these trees (i.e., for the Douglas fir layer). For the salal layer, $1-\mathrm{m}^{2}$ sample measurements made in each of the cut subplots on May 21, 1981, were used to estimate $a$.

The leaf wetness variable for each layer was estimated using the ratio of the layer water storage $(C)$ to the maximum water storage of the layer $(S)$. The value of $S$ for the Douglas fir layer was determined by plotting 24-hour throughfall (above the salal) against the corresponding rainfall using data of Spittlehouse [1981] for 1978. Rutter et al. [1971] showed that the negative intercept of the line of unit slope along the upper limit of the throughfall data gives the value of $S$. This was found to be $0.6 \mathrm{~mm}$. Since the value of $a$ of the Douglas fir layer in 1978 was 5 , the average depth of water on the leaves was $0.12 \mathrm{~mm}$. This was very close to the depth of water after drainage on a foliated Douglas fir branch sprayed in the laboratory [Spittlehouse and Black, 1982]. The value of $S$ for the salal layer was approximated by multiplying salal $a$ by 0.12 . The value of $C$ was calculated for each time $j$ using the following water balance equation for each layer:

$$
C_{j}=C_{j-1}+\left[(1-p) P_{j}-E_{l j}-Q_{j}\right] \Delta t
$$

where $\Delta t$ is $15 \mathrm{~min}$, and $P_{j}$ and $Q_{j}$ are the rates of rainfall and drainage of intercepted water respectively for the interval between $j-1$ and $j$. The free throughfall coefficient $p$ was calculated by taking the average of the ratio of 24 hour throughfall (above salal) to rainfall for 5 days from Spittlehouse [1981], where $P<S$ [Rutter et al., 1971]. It was found to be 0.6 . Drainage was assumed to be zero until $C_{j}$ exceeded $S$. At this point drainage was calculated as the amount by which ((1 $\left.-p) P_{j}-E_{I j}\right) \Delta t$ exceeded the remaining water storage capacity of the leaves $\left(S-C_{j-1}\right)$.

\section{Root Zone Water Balance Equation}

The course of average root zone volumetric water content $(\theta)$ during two summer periods was calculated using the fol- lowing water balance equation applied to the stand and its single-layer root zone

$$
\theta_{k}=\theta_{k-1}+\left(P_{k}-E_{k}-F_{k}\right) \Delta t / \zeta
$$

where $P_{k}, E_{k}$, and $F_{k}$ are the rates of rainfall, evapotranspiration, and root zone drainage at time $k$, respectively; $\Delta t$ is the time interval between $k$ and $k-1$ (1 hour except for when $W_{i}>0$ and then $\Delta t$ is $15 \mathrm{~min}$ ); and $\zeta$ is root zone depth. Evapotranspiration rates were calculated using (1) through (7) with the canopy divided into two layers (tree and understory). Drainage from the root zone was calculated as a function of $\theta$ $\left(F\left(\mathrm{~mm} \mathrm{~d}^{-1}\right)=100(\theta / 0.3)^{15}\right)$ [Spittlehouse and Black, 1981a]. During most of the summer, drainage was a small term in the root zone water balance equation so that $\theta$ was largely determined by rainfall and evapotranspiration.

\section{Testing the Evapotranspiration and Root Zone Water Balance Equations}

During July to September 1981 and May to July 1982, $\theta$ was measured at 1- to 2 -week intervals using the neutron moderation technique with a calibrated [Kelliher, 1985] probe (model CPN 503, Campbell Pacific Nuclear Corp., Pacheco, Calif.) being lowered into aluminum access tubes. There were 3 or 4 tubes in each subplot. Thermocouple psychrometers and tensiometers were used to measure $\Psi_{s}$ every 2-7 days. A pair of psychrometers and a tensiometer were installed at 150 mm depth intervals down to bedrock in each subplot of plot 2 . Measured values of $\theta$ and $\Psi_{s}$ were compared during the two summer periods with calculated values obtained using (8) and a soil water retention curve determined using neutron probe, tensiometer, and thermocouple psychrometer measurements at the site $\left(\Psi_{s}(\mathrm{MPa})=-0.005(\theta / 0.3)^{-6.5}\right)$.

Forest evapotranspiration was measured on 4 days in August 1982 using the Bowen ratio-energy balance technique. Half-hourly measurements of the Bowen ratio $(\beta)$ were made using a dc-powered rotating psychrometric apparatus described by Spittlehouse and Black [1981b]. The apparatus was located at the top of a 15-m-tall tower adjacent to the four plots, with the vertical separation between the two psychrometers being $3 \mathrm{~m}$. The lower psychrometer was about $1 \mathrm{~m}$ above the tops of the trees. Forest evapotranspiration was calculated using

$$
E=\left(R_{n a}-G-M\right) /(L(1+\beta))
$$

where $M$ is the rate of canopy heat storage estimated following Stewart and Thom [1973]. This measurement of $E$ was considered to include tree and understory transpiration and soil evaporation, since the area where understory had been removed was small and $20 \mathrm{~m}$ from the tower in a direction at right angles to the prevailing wind direction. These measurements of $E$ were compared to calculated values obtained using (1) $-(8)\left(W_{i}=0\right)$ applied to a two-layer canopy (trees and understory) plus soil evaporation.

Stomatal resistance measurements were made using a ventilated diffusion porometer described by Tan et al. [1977]. Hourly measurements were made on the two trees and salal in one plot from sunrise until late afternoon on Auguist 12 and 20,1981 , and on the two trees only on June $9,17,23$, and 30 , 1982. These measurements were used to check the applicability of the $r_{s}$ functions mentioned earlier to the trees and salal in 1981 and 1982 and to assess the accuracy of the rates of tree and understory transpiration calculated using (1). 
TABLE 1. Daily (24-hour) Net Radiation Flux Density Above the Forest $\left(R_{n g}\right)$ and Daily Measured and Calculated Values of Evapotranspiration Rate $(E)$ Following Initialization of Calculations on August 20,1982, When Measured $\theta$ was $0.16 \mathrm{~m}^{3} \mathrm{~m}^{-3}\left(\Psi_{s}=-0.3 \mathrm{MPa}\right)$

\begin{tabular}{lrrrr}
\hline & \multicolumn{4}{c}{ Date (August, 1982) } \\
\cline { 2 - 5 } & \multicolumn{1}{c}{24} & \multicolumn{1}{c}{25} & 26 & 27 \\
\hline$R_{\text {na }}$ & 11.5 & 11.6 & 12.6 & 1.4 \\
Measured $E$ & 1.8 & 2.2 & 1.8 & 0.2 \\
Calculated $E$ & 1.9 & 2.0 & 2.0 & 0.3 \\
\hline
\end{tabular}

$R_{n a}$ are given in $\mathrm{MJ} \mathrm{m}^{-2} \mathrm{~d}^{-1}$ and $E$ in $\mathrm{mm} \mathrm{d}^{-1}$. Root mean square errors in measured and calculated $E$ were approximately $0.2-0.3 \mathrm{~mm}$ $\mathrm{d}^{-1}$ for August 24-26 and $0.1 \mathrm{~mm} \mathrm{~d}^{-1}$ for August 27.

\section{RESULTS AND Discussion}

\section{Measured and Calculated Daytime Evapotranspiration Rates}

There was generally good agreement between daily values of $E$ measured during the 4-day test period using the energy balance-Bowen ratio and values calculated for the stand with understory present (Table 1). Agreement was not as good when comparing the daytime courses of measured and calculated $E$ (Figure 1). However, both measured and calculated $E$ was highest for the 2-hour period prior to noon on August 25, 1982. Calculated Douglas fir $r_{s}$ increased markedly after 1400 hours (>6000 s m $\mathrm{m}^{-1}$ ) owing to the high values of $D$, and calculated salal $E$ was highest for the period $1100-1400$ hours $\left(\approx 0.1 \mathrm{~mm} \mathrm{~h}^{-1}\right)$. Measurement error accounts for some of the disagreement, since Bowen ratios were high $(\geq 2)$ on August 24-26 and wet and dry bulb gradients small on August 27 [Spittlehouse and Black, 1980].

\section{Forest Floor Evaporation After Salal Removal}

For $\theta$ less than $\mathbf{0 . 1 8 5}$, forest floor diffusive resistance was linearly related to $\theta$ (Figure 2). On 3 days when $\theta>0.185, r_{c 0}$

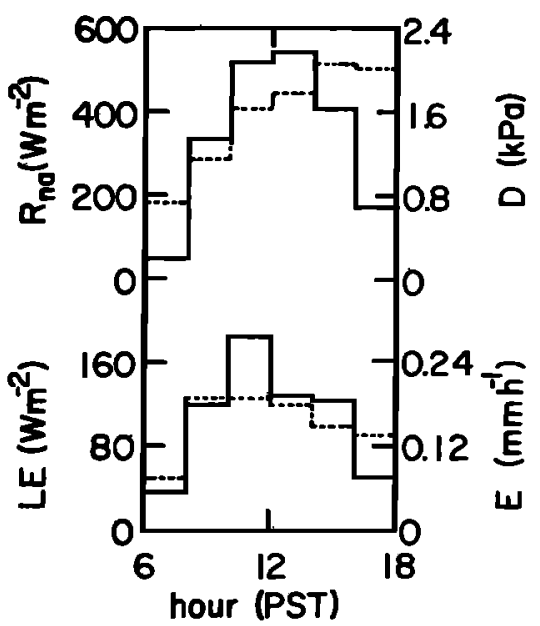

Fig. 1. Courses of net radiation flux density and vapor pressure deficit above the lorest $\left(R_{n a}\right.$ (solid lines) and $D$ (dashed lines), respectively) and measured (solid lines) and calculated (dashed lines) forest evapotranspiration rate (E) (with understory) on August 25, 1982, a clear day when average zone soil water potential $\left(\Psi_{s}\right)$ was about -0.7 MPa. Errors in measured $E$ were approximately $0.02-0.04 \mathrm{~mm} \mathrm{~h}^{-1}$ [Spittlehouse and Black, 1980]. Root-mean-square errors in calculated $E$ were $0.04-0.06 \mathrm{~mm} \mathrm{~h}^{-1}$ as determined by differentiation of (1) applied to two layers and soil. $A 10 \%$ error was assumed for $D_{i}$, a $20 \%$ error for $\left(R_{n t}-G\right)$, and a $30 \%$ error for the transfer resistances, $L E_{0}$ and $R_{n 0}$.

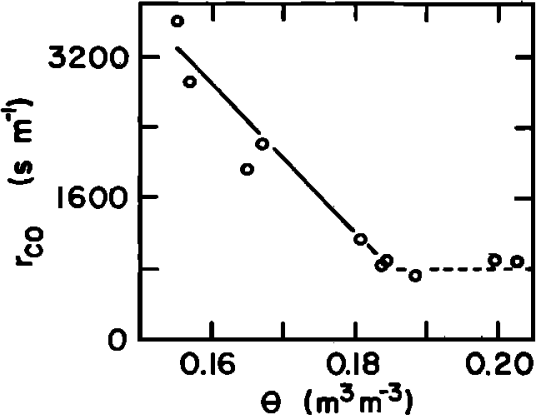

Fig. 2. Relationship between forest floor diffusive resistance ( $\left.r_{c 0}\right)$ and average root zone soil water content $(\theta)$ in the cut subplot of plot 2 for 10 days in July and August 1981. For $\theta$ less than $0.185, r_{c o}$ (s $\left.\mathrm{m}^{-1}\right)=-83000 \theta+16100\left(R^{2}=0.96\right)$ as shown by the solid line For $\theta$ greater than $0.185, r_{c 0}$ was $800 \mathrm{~s} \mathrm{~m}^{-1}$, on average, as shown by the dashed line.

was $700 \mathrm{~s} \mathrm{~m}^{-1}(\theta=0.189)$, and $900 \mathrm{~s} \mathrm{~m}^{-1}(\theta=0.200$ and $0.203)$. This meant that $E_{0}$ was limited by a dry surface layer whose thickness $\left(l_{d}\right)$ can be related to $r_{c 0}$ using [Denmead, 1984; Novak and Black, 1985]

$$
l_{d}=r_{c 0} f_{d}\left(\varepsilon_{d}-\theta_{d}\right) \kappa_{v}
$$

where $f_{d}$ is a "tortuosity" factor (0.66); $\varepsilon_{d}$ and $\theta_{d}$ are the porosity and volumetric water content of the dry layer; and $\kappa_{v}$ is the molecular diffusivity for water vapor $\left(24.9 \times 10^{-6} \mathrm{~m}^{2} \mathrm{~s}^{-1}\right.$ at $25^{\circ} \mathrm{C}$ ). For the forest floor, $\varepsilon_{d}$ and $\theta_{d}$ were taken from Plamondon [1972] as 0.88 (i.e., bulk density $=150 \mathrm{~kg} \mathrm{~m}^{-3}$, organic matter density $=1300 \mathrm{~kg} \mathrm{~m}^{-3}$ [Van Wijk and De Vries, 1963], and 0.20 (i.e., matric potential $=-1.5 \mathrm{MPa}$ ). Using these values and $r_{c 0}=700 \mathrm{~s} \mathrm{~m}^{-1}$ in (10) results in $l_{d}=8$ $\mathrm{mm}$. Field observations support this calculation. At about midday on the day following an evening irrigation equivalent to $100 \mathrm{~mm}$ of rain, the forest floor surface of a cut area (i.e., salal cut and removed) adjacent to the four plots was observed to be dry. The above value of $l_{d}$ suggests that the top $8 \mathrm{~mm}$ of forest floor consisted of rapidly draining litter (i.e., undecomposed leaves and twigs), while the bottom $2-12 \mathrm{~mm}$ was humified with some water storage capacity. The interface between the organic layer and mineral soil was moist until $r_{\mathrm{c} 0}$ reached

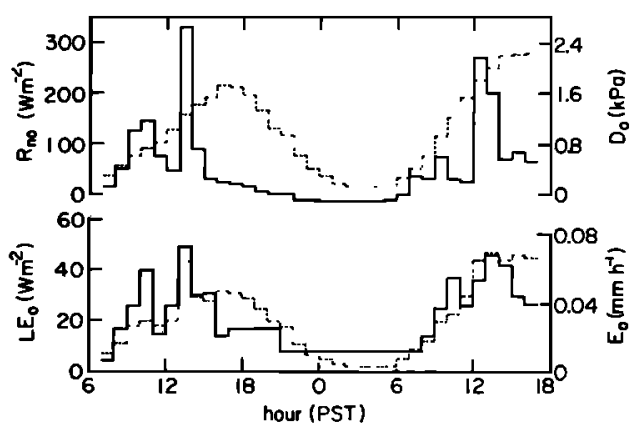

Fig. 3. Courses of net radiation flux density and vapor pressure deficit above the forest floor $\left(R_{\mathrm{no}}\right.$ (solid lines) and $D_{0}$ (dashed lines), respectively) and measured (solid lines) and calculated (dashed lines) forest floor evaporation rate $\left(E_{0}\right)$ in the cut subplot of plot 2 on July 24-25, 1981, two clear days when average root zone soil water potential $\left(\Psi_{s}\right)$ was about $-0.05 \mathrm{MPa}$. Standard deviations for measured $E_{0}$ values were typically $0.004 \mathrm{~mm} \mathrm{~h}^{-1}$ at night and $0.015 \mathrm{~mm} \mathrm{~h}^{-1}$ during the daytime. Root-mean-square errors for calculated $E_{0}$ values were similar. These errors were determined by differentiation of (1) with $\delta_{0}=0$. A $20 \%$ error was assumed for $\left(R_{n 0}-G\right)$ and $r_{c 0}$, a $10 \%$ error for $D_{0}$, and a $30 \%$ error for $r_{A 0}$. 


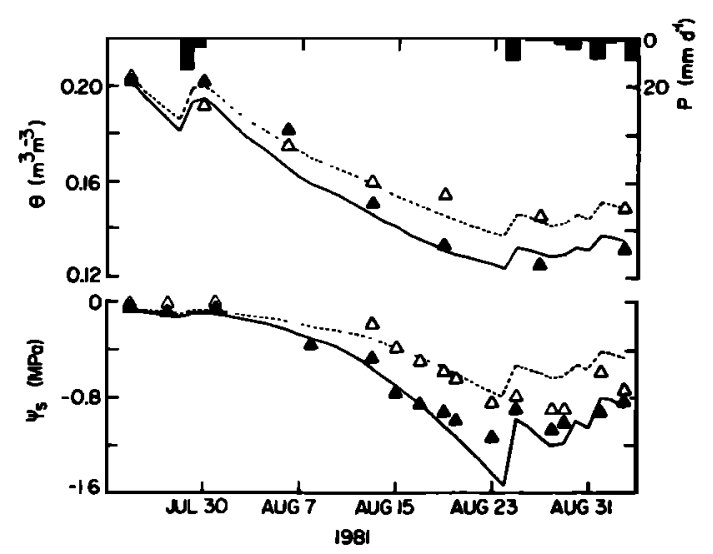

Fig. 4. Courses of measured (symbols) and calculated (lines) average root zone soil water content $(\theta)$ and soil water potential $\left(\Psi_{s}\right)$ in the cut (open triangles and dashed curves) and uncut (closed triangles and solid curves) subplots of plot 2 for the period July 24 to September 3,1981. Standard deviations for measured $\theta$ and $\Psi_{s}$ were $0.01-0.02 \mathrm{~m}^{3} \mathrm{~m}^{-3}$ and $0.1-0.2, \mathrm{MPA}$, respectively. Also shown is the daily rainfall rate $(P)$.

$850-1500 \mathrm{~s} \mathrm{~m}^{-1}(\theta=0.184-0.176)$. For $\theta=0.125\left(\Psi_{s}=-1.5\right.$ $\mathrm{MPa}), l_{d}$ was $68 \mathrm{~mm}$ so that the top 48-58 $\mathrm{mm}$ of soil was dry.

For July 24-25, 1981, two consecutive clear days when $\Psi_{s}$ was about $-0.05 \mathrm{MPa}$, setting $r_{c 0}=900 \mathrm{~s} \mathrm{~m}^{-1}$ provided agreement between calculated and measured daily values of $E_{0}\left(0.6 \mathrm{~mm} d^{-1}\right)$. Hourly values of calculated $E_{0}$ generally agreed with lysimeter measurements in the cut subplot of plot 2 (Figure 3). Eddy diffusive resistances varied from 10-50 s $\mathrm{m}^{-1}$ and were highest for the period 0200-0600 hours on July 25 . The high variability in the measured values of $R_{n 0}$ and $E_{0}$ was due to sun flecks which were generally common to the net radiometer and lysimeters. About $16 \%$ of the daily measured $E_{0}$ occurred at night (2200-0600 hours Figure 3), while for the calculations the value was $10 \%$.

\section{Measured and Calculated Courses of Average} Root Zone Volumetric Water Content

Using equations (1) to (4). Calculations of the courses of $\theta$ using the complete evapotranspiration theory and water balance equations were made for the eight subplots for the periods July 24 to September 3, 1981, and May 27 to July 1, 1982. There was good agreement between measured courses of $\theta$ in cut and uncut subplots (Figures 4 and 5 and Table 2). In particular, there was excellent agreement in the measured and

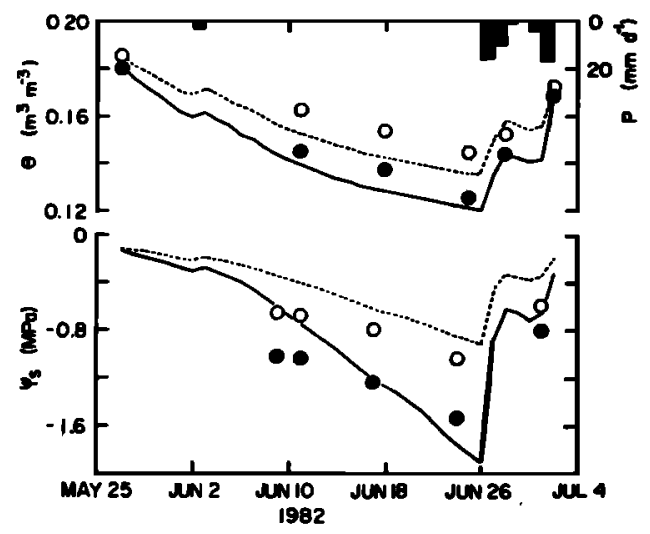

Fig. 5. Same as for Figure 4 except for May 27 to July 1, 1982, (open circles and dashed curves) for cut and (solid circles and solid curves) for uncut subplots.
TABLE 2. Average Values of the Minimum Measured and Calculated Average Root Zone Water Content $\left(\mathrm{m}^{3} \mathrm{~m}^{-3}\right)$ in the Cut $(C)$ and Uncut $(U)$ Subplots

\begin{tabular}{lccccc}
\hline & \multicolumn{2}{c}{ August 27, 1981} & & \multicolumn{2}{c}{ June 25, 1982} \\
\cline { 2 - 3 } \cline { 5 - 6 } Subplot & Measured & Calculated & & Measured & Calculated \\
\hline 1U & 0.14 & 0.14 & & 0.14 & 0.12 \\
1C & 0.13 & 0.14 & & 0.15 & 0.14 \\
2U & 0.13 & 0.13 & & 0.12 & 0.12 \\
2C & 0.15 & 0.15 & & 0.14 & 0.14 \\
3U & 0.14 & 0.13 & & 0.14 & 0.12 \\
3C & 0.17 & 0.15 & & 0.17 & 0.14 \\
4U & 0.16 & 0.14 & & 0.16 & 0.13 \\
4C & 0.17 & 0.16 & & 0.16 & 0.15 \\
Means & & & & \\
$\quad U$ & 0.14 & 0.13 & & 0.14 & 0.12 \\
$C$ & 0.16 & 0.15 & & 0.16 & 0.14 \\
\hline
\end{tabular}

For plots 2 and 3 (but not plots 1 and 4) the difference between measured values in cut and uncut subplots was statistically significant ( $95 \%$ probability) in both years.

calculated differences in $\theta$ between paired subplots. Salal understory removal resulted in slightly higher values of $\theta$ and much higher values of $\Psi_{s}$. Because of the large value of $\Delta \Psi_{s}$ / $\Delta \theta$ for this gravelly sandy loam soil at low values of $\theta$, a small decrease in $\theta$ corresponded to a large decrease in $\Psi_{s}$ (Figures 4 and 5).

Effect of assuming $r_{A i}=0$ and $r_{a i}=0$. Considerable simplification of the evapotranspiration theory is achieved when $W_{i}=0$ by using the limit $r_{A i} \rightarrow 0$ in the theory so that $E_{i}^{\prime}=$ $\rho c_{p} D_{i} / r_{c i}$, where $r_{c i}=r_{s l} / a_{i}$. Working in the same stand as in this study, Tan et al. [1978] obtained good agreement between energy balance-Bowen ratio evapotranspiration measurements and values calculated using the above procedure in 1975 following heavy thinning of the stand. Use of this procedure in the cut subplot of plot 2 (salal understory cut and removed) for the rainless period July 30 to August 18,

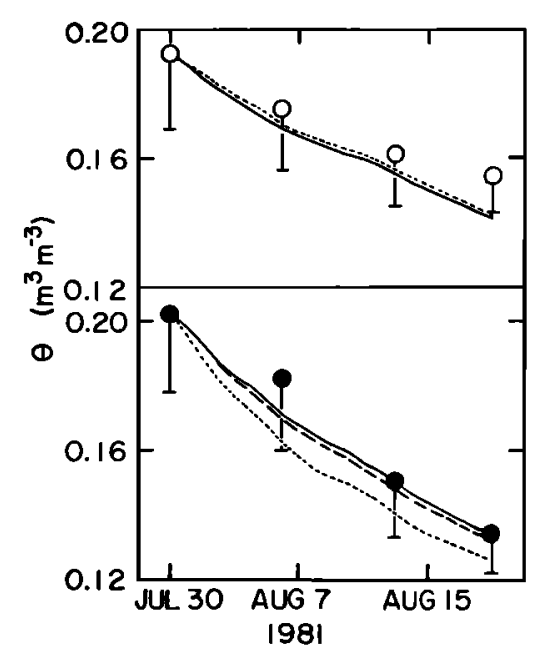

Fig. 6. Courses of measured (symbols) and calculated (curves) average root zone soil water content $(\theta)$ in the cut (open circles) and uncut (closed circles) subplots of plot 2 for the rainless period July $\mathbf{3 0}$ to August 18, 1981. Values of $\theta$ were calculated with eddy diffusive and leaf boundary layer resistances (solid lines), without eddy diffusive resistances (long-dashed lines), and without eddy diffusive and leaf boundary layer resistances (short-dashed lines). For the cut subplot there was no significant difference between calculations with both sets of resistances and without eddy diffusive resistances. Error bars are one standard deviation. 
TABLE 3. Average Calculated Values of Total Evapotranspiration $(E)$, Transpiration $\left(E_{T}{ }^{\prime}\right)$, Evaporation of Intercepted Water $\left(E_{r}\right)$, and Forest Floor Evaporation $\left(E_{0}\right)$ in the Cut $(C)$ and Uncut $(U)$ Subplots for Periods July 24 to September 3, 1981, and May 27 to July 1, 1982

\begin{tabular}{cccccccr}
\hline & & \multicolumn{2}{c}{$E_{T}^{\prime}$} & & \multicolumn{2}{c}{$E_{I}^{\prime}$} \\
\cline { 3 - 4 } Subplot & $E$ & Fir & Salal & & Fir & Salal & $E_{0}$ \\
\hline & & & 1981 & & & \\
$U$ & 88 & 39 & 28 & 15 & 3 & 3 \\
$C$ & 81 & 51 & & 15 & & 15 \\
$U$ & 63 & 21 & 20 & 17 & 2 & 3 \\
$C$ & 59 & 32 & & 17 & & 10 \\
\hline
\end{tabular}

Values are given in millimeters.

1981 , resulted in only slightly higher calculated $\theta$ values than those obtained when $r_{A i}$ was not assumed to be negligible (Figure 6). This is to be expected, since $r_{A i}$ is much smaller than $r_{s i}$ for Douglas fir so that $r_{s i} / a_{i}$ is a good approximation of the Douglas fir canopy resistance [Tan et al., 1978]. The reason for the small difference between calculated $\theta$ values (with $r_{A i}$ included) in Figure 6 and those in Figure 4 is due to the difference in the starting dates for calculations in the two figures. For salal, the magnitudes of $r_{A i}$ and $r_{c l}$ are similar so that neglecting $r_{A i}$ for salal and Douglas fir layers resulted in much lower calculated $\theta$ values in the uncut subplot of plot 2 for the same rainless period (Figure 6).

A reasonable assumption for many stands is that the eddy diffusive resistances $\left(r_{A i}\right)$ within and above the tree canopy are small compared to stomatal and boundary layer resistances [Stewart, 1984]. Writing the theory with $r_{a i}=0$ is further justified in view of the doubt in the validity of concept of eddy diffusive resistance within the plant canopy [Raupach and Thom, 1981]. This assumption does not limit the theory to dry leaf canopies as was the case with $r_{A i}=0$. As expected, the former assumption resulted in $\theta$ in the uncut subplots being slightly lower than when $r_{a i}$ and $r_{b i}$ are included (Figure 6).

When $r_{A i}$ for both layers was included, calculated tree transpiration in the uncut subplot for this 20-day period was 25 $\mathrm{mm}$. The corresponding value was $20 \mathrm{~mm}$ when $r_{A i}$ for both layers were neglected. The difference between these two values resulted from more salal understory transpiration being calculated using the latter procedure. Since salal stomatal resistance characteristics and leaf area index remained relatively constant from 1975-1981, it appears that the reduction in salal transpiration from 1975-1981 resulted from forest canopy closure leading to a reduction in the ratio of below to above tree canopy wind speed and an increase in $r_{A i}$ for the salal layer. Calculated tree transpiration for the 20-day period with $r_{a i}=$ 0 was $24 \mathrm{~mm}$, only slightly less than with the eddy diffusive resistance included.

\section{Partitioning of Evapotranspiration in Cut and Uncut Subplots}

Table 3 gives the calculated values of total evapotranspiration, transpiration and interception of Douglas fir and salal, and forest floor evaporation for cut and uncut subplots for the periods shown in Figures 4 and 5. Calculated values of total $E$ for the uncut subplots were slightly larger than those for the cut subplots in both years. Throughout these periods, calculated values of $E$ of the uncut subplots were also slightly higher than in the cut subplots. This was also found using a simple water balance analysis of the $\theta$ and $P$ data which used the approximation $E \approx-(\Delta \theta / \Delta t) \zeta+P$. The only exception was for the period August 6-19, 1981, in plot 2 when the water balance values of $E$ were 2.4 and $1.1 \mathrm{~mm} \mathrm{~d}^{-1}$ for the uncut and cut subplots, respectively, compared to calculated average values of 1.7 and $1.5 \mathrm{~mm} \mathrm{~d}^{-1}$ respectively.

Calculated transpiration rates of the trees in the cut subplots were slightly higher than those in the uncut subplots for the first 19 days of the 1981 period and first 11 days of the 1982 period but were considerably higher during the rest of the respective periods (Figure 7). On August 12, 1981, calculated tree transpiration rates were 1.5 and $1.1 \mathrm{~mm} \mathrm{~d}^{-1}$ in the cut and uncut subplots of plot 2 (leaf area index was 5 for both trees) respectively. The corresponding values on August 20 were 1.1 and $0.5 \mathrm{~mm} \mathrm{~d}^{-1}$. Using (1) and $r_{s}$ measurements made at about the midcrown height of the trees in plot 2, tree transpiration rates were estimated to be 1.4 and $1.1 \mathrm{~mm} \mathrm{~d}^{-1}$ on August 12 and 0.8 and 0.6 on August 20, 1981, in cut and uncut subplots, respectively. There was not as good agreement between calculated and estimated tree transpiration rates in plot 2 for June 9, 17, 23, and 30, 1982; however, the differences between the cut and uncut subplots were in good agreement. During the 1981 and 1982 periods, salal removal resulted in an average increase in calculated tree transpiration rate of 31 and $52 \%$, respectively, in the four plots. Calculations indicated that the increase in tree transpiration rate was greatest in plot 3 where salal leaf area index ( 3 and 2.4 in 1981 and 1982, respectively) was highest and was least in plot 4 where salal leaf area index was lowest (2.1 and 1.7 in 1981 and 1982).

Calculated values of total salal transpiration plus forest floor evaporation below the salal were about twice those of forest floor evaporation after salal removal in the 1981 and 1982 periods. This largely accounts for the increased tree transpiration following salal removal, since Douglas fir interception in adjacent subplots was identical and salal interception was a small term in the water balance. McNaughton and Jarvis [1983] expressed the evapotranspiration rate in terms of the equilibrium evaporation rate $\left(E_{e q}=[s /(s+\gamma)]\left(R_{n}\right.\right.$ $-G) / L)$ and the equilibrium vapor pressure deficit $\left(D_{e q}=\right.$ $\left.[s /(s+\gamma)] \gamma r_{c}\left(R_{n}-G\right) / \rho c_{p}\right)$. For the salal, small canopy resistances [Tan et al., 1978] resulted in $D_{e q}<D$ above the salal canopy and the ratio of the 24-hour average salal transpira-

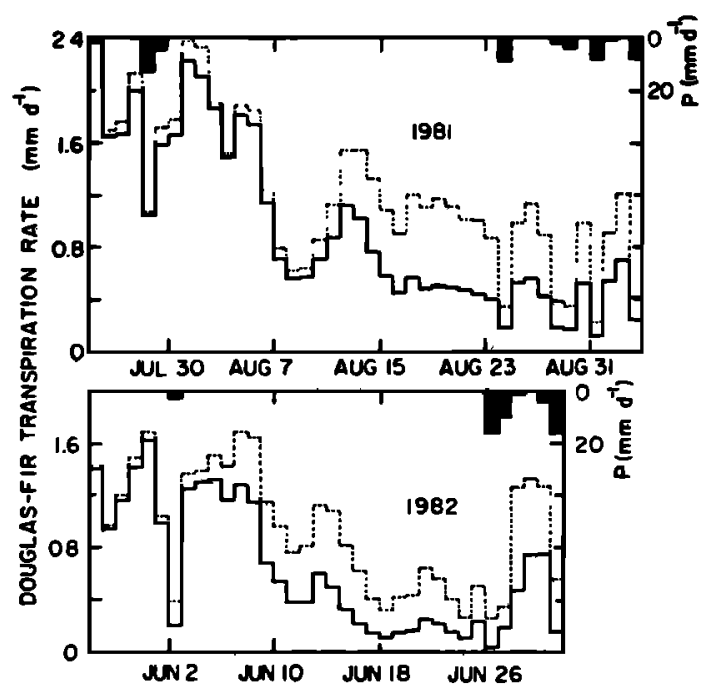

Fig. 7. Courses of calculated tree transpiration rates in the cut (dashed lines) and uncut (solid lines) subplots of plot 2 for the periods July 24 to September 3, 1981, and May 27 to July 1, 1982. Rootmean-square errors were typically $0.2-0.4 \mathrm{~mm} \mathrm{~d}^{-1}$ when calculated as described in the Figure 1 caption. Also shown is the daily rainfall rate $(P)$. 
tion and forest floor evaporation rate to the corresponding value of $E_{e q}$ being 2.0-2.7 during the period July 24 to August 20,1981 . For the forest floor after salal removal, large surface diffusive resistances generally resulted in $D_{e q}>D$ above the forest floor and the ratio of the 24-hour average evaporation rate to $E_{\text {eq }}$ being $0.5-1.0$ during the same period.

The evapotranspiration theory was developed for extensive homogeneous surfaces so that its application in the cut subplots included the use of below-tree canopy values of $D$ and $T_{\text {air }}$ largely determined by the presence of salal in the surrounding forest. Values of below-tree canopy $D$ and $T_{\text {air }}$ would be expected to be higher following extensive salal removal; however, it is difficult to estimate the magnitude of the increase. McNaughton and Jarvis [1983] show that the $D$ above a conifer forest canopy is likely to be well coupled to the outer mixed portion of the planetary boundary layer. Consequently, they argue that a $50 \%$ reduction in forest leal area index would not result in an increase in above-forest $D$ and therefore would result in a significant reduction in forest evapotranspiration. Since $D$ below the tree canopy in this study was well correlated to that above (in agreement with the results reported by Stewart [1984] for Thetford forest), it is likely that only a slight increase in below-tree canopy $D$ would result from extensive salal removal. Further research involving understory removal over an extensive area is required to answer this question.

\section{CoNCLUSIONS}

Shuttleworth's [1979] evapotranspiration theory with canopy and root zone water balance models proved to be reasonably accurate and practical in calculating the courses of $\theta, \Psi_{s}$, and tree transpiration during extended periods in the growing season. The difficulty in using the theory is in estimating the transfer resistances $\left(r_{s i}, r_{b i}, r_{a i}\right.$, and forest floor diffusive resistance), although $r_{s i}$ is often available from physiological studies. Simplifying the evapotranspiration theory by neglecting $r_{a i}$ above and within the canopy resulted in very small decreases in the courses of $\theta$ and tree transpiration rate. Further simplification for dry canopy conditions $\left(W_{1}=0\right)$ by assuming $r_{A i}=0$ caused an overestimation of understory transpiration which resulted in an underestimation of the courses of $\theta, \Psi_{s}$, and tree transpiration in uncut subplots. This simplification resulted in little change in cut subplots, since $r_{A i}$ is much smaller than $r_{s i}$ for Douglas fir.

Calculations showed that the slightly higher values of $\theta$ as a result of understory removal corresponded to higher tree transpiration rates. During early (June 1982) and late (August 1981) growing season drying periods, most of the difference in tree transpiration occurred during the second half of the period due to the large value of $\Delta \Psi_{s} / \Delta \theta$ of the soil water retention curve for low values of $\theta$ and stomatal closure by Douglas fir where salal remained. Increase in tree transpiration as a result of understory removal was greatest where understory leaf area index was highest.

\section{APPENDix: DeRIVATION OF Equations}

$$
\text { (1), (4), AND (5) }
$$

The Penman-Monteith equation for a canopy layer $i$ neglecting energy storage is

$$
E_{i}^{\prime}=\frac{s\left(R_{n i}-R_{n i-1}\right)+\rho c_{p} D_{i-1} / r_{H a i}}{L\left(s+\gamma r_{V a i} / r_{H a i}\left(1+\left(r_{c i} / r_{V a i}\right)\right)\right)}
$$

where $R_{n i-1}$ is the net radiation below the layer, and $D_{i-1}$ is the vapor pressure deficit within the layer but outside the leaf

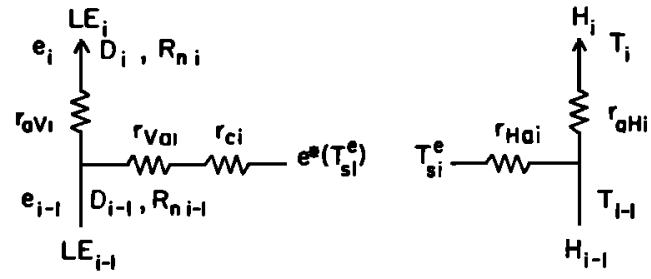

Fig. 8. Electrical analogue for the vertical transfer of latent and sensible heat fluxes above canopy layer $i\left(L E_{\mathrm{l}}\right.$ and $\left.H_{\mathrm{b}}\right)$ where $T_{s 2}{ }^{e}$ is the "effective" surface temperature of the layer (i.e., wet and dry portions), and other symbols are defined in the text.

boundary layer. This equation gives the water vapor flux density from an equivalent extended isothermal one-sided leaf with boundary layer resistances $r_{\mathrm{Hai}}$ and $r_{\mathrm{Vai}}$ to sensible heat and vapor transfer, respectively, and a surface or canopy resistance $r_{c i}$ to vapor transfer. The water vapor flux density on a ground area basis from a canopy layer of hypostomatous leaves with a projected leaf area index $\left(a_{i}\right)$ and a fraction of the leaf area wet $\left(W_{1}\right)$ can be written as

$$
\begin{aligned}
E_{i}^{\prime}= & W_{i} a_{i}\left[\frac{s\left(R_{n i}-R_{n i-1}\right) / a_{i}+\rho c_{p} D_{i-1} /\left(r_{H i} / 2\right)}{L\left(s+\gamma r_{V i} / r_{H i}\right)}\right] \\
& +\left(1-W_{i}\right) a_{\imath}\left[\frac{s\left(R_{n i}-R_{n i-1}\right) / a_{i}+\rho c_{p} D_{i-1} /\left(r_{H i} / 2\right)}{L\left(s+\gamma\left(r_{V i}+r_{s i}\right) /\left(r_{H i} / 2\right)\right)}\right]
\end{aligned}
$$

The first bracketed term of (A2) is the evaporation rate from the average wet leaf on a projected leaf area basis in layer $i$, the second bracketed term is the transpiration rate from the average dry hypostomatous leaf on a projected leaf area basis in layer $i, r_{s i}$ is the leaf stomatal resistance of the side with stomata, and $r_{H i}$ and $r_{V i}$ are leaf boundary layer resistances on one side. In order that (A2) can be rewritten in the form of (A1) by making $r_{c i}$ a function of $W_{i}$, we require $r_{H a i}=r_{H i} /\left(2 a_{i}\right)$ and

$$
\begin{aligned}
& \frac{1}{s+\gamma\left(r_{V a i} / r_{H a i}\right)\left(1+\left(r_{c i} / r_{V a i}\right)\right)} \\
& =\frac{W_{i}}{s+\gamma r_{V i} / r_{H i}}+\frac{1-W_{i}}{s+\gamma\left(r_{V i}+r_{s i}\right) /\left(r_{H i} / 2\right)}
\end{aligned}
$$

Solving for $r_{c i}$ we have

$$
\begin{aligned}
r_{c i}= & {\left[\frac{W_{i}}{(s / \gamma) r_{H a i}+r_{V i} / 2 a_{i}}\right.} \\
& \left.\quad+\frac{1-W_{i}}{(s / \gamma) r_{H a i}+\left(r_{V i}+r_{s i}\right) / a_{i}}\right]^{-1}-(s / \gamma) r_{H a i}-r_{V a i}
\end{aligned}
$$

where $r_{V a i}=r_{V i} /\left(2 a_{i}\right)$ which reduces to (4) when $r_{V i}$ and $r_{H i}$ are assumed to be equal and written as $r_{b i}$.

Since (A2) can be written in the form of (A1), the canopy layer has an effective leaf temperature $\left(T_{s i}{ }^{2}\right)$ [Campbell, 1977]. Applying Ohm's Law to the electrical analogue of the model for canopy layer $i$ shown in Figure 8, the relationships between fluxes and resistances can be written as [Shuttleworth, 1979, p. 321]

$$
\begin{gathered}
T_{i}-T_{i-1}=-H_{i} r_{a H i} / \rho c_{p} \\
T_{i-1}-T_{s i}{ }^{e}=-\left(H_{i}-H_{i-1}\right)\left(r_{H i} / 2 a_{i}\right) / \rho c_{p} \\
e_{i}-e^{*}\left(T_{s i}{ }^{e}\right)=-L E_{i} r_{a V i} \gamma / \rho c_{p} \\
-L\left(E_{i}-E_{i-1}\right)\left(r_{c i}+\left(r_{V i} / 2 a_{i}\right)\right) \gamma / \rho c_{p}
\end{gathered}
$$


where $H$ is the sensible heat flux density; $e$ is the vapor pressure; and $e^{*}\left(T_{s i}{ }^{e}\right)$ is the saturation vapor pressure at the effective leaf temperature. Using the Penman transformation, we have

$$
e_{i}-e^{*}\left(T_{s i}{ }^{2}\right)=D_{i}+s\left(T_{i}-T_{i-1}\right)+s\left(T_{i-1}-T_{s i}{ }^{e}\right)
$$

where, since $T_{s i}{ }^{e}-T_{i}$ is not large, the same value of $s$ is used for both temperature differences. The energy balance equation for all layers 1 to $i$ (neglecting energy storage) is

$$
R_{n i}-G=H_{i}+L E_{i}
$$

where $L E_{i}$ is the latent heat flux density above layer $i$. Substituting (A5), (A6), and (A7) into (A8), using (A9) and dividing by $L$, we have

$$
E_{l}=\frac{s\left(R_{n i}-G\right)+\rho c_{p}\left(D_{i}+\delta_{i}^{\prime}\right) / r_{A H i}}{L\left(s+\gamma\left(r_{A V l} / r_{A H}\right)\left(1+\left(r_{c i} / r_{A V i}\right)\right)\right)}
$$

where

$$
\begin{aligned}
\delta_{i}^{\prime}=\left[L E_{i-1}\left[\left(r_{c i}+\left(r_{V i} / 2 a_{i}\right)\right) \gamma+\left(r_{H i} / 2 a_{i}\right) s\right]\right. \\
\left.-s\left(R_{n i-1}-G\right)\left(r_{H i} / 2 a_{i}\right)\right] / \rho c_{\mathrm{p}}
\end{aligned}
$$

with $r_{A H i}=r_{H i} / 2 a_{i}+r_{a H i}$ and $r_{A V i}=r_{V i} / 2 a_{i}+r_{a V i}$. Equation (A10) is the same as (9) in the work by Shuttleworth [1979]. Subtracting $E_{i-1}$ from (A10) and assuming similarity (i.e., $r_{H i}=r_{V i}=r_{b i}$ and $r_{a H i}=r_{a V i}=r_{a i}$ ) give (1).

The rate of evaporation of intercepted water from layer $i\left(E_{I i}^{\prime}\right)$ is obtained by multiplying the fraction of leaf area (one side) that is completely wet $\left(W_{i}\right)$ by (A1) with $r_{c i}=0$ which gives

$$
E_{I^{\prime}}{ }^{\prime}=\frac{W_{i}\left[s\left(R_{n i}-R_{n i-1}\right)+\rho c_{p} D_{i-1} / r_{H a i}\right]}{L\left(s+\gamma\left(r_{V a i} / r_{H a i}\right)\right)}
$$

Dividing (A12) by (A1), assuming similarity (i.e., $r_{H a i}=r_{V a i}=$ $\left.r_{b i} / 2 a_{i}\right)$, making use of (4) and rearranging give (5).

Acknowledgments. This research was supported by a grant from the Natural Science and Engineering Research Council of Canada and a contract from the British Columbia Ministry of Forests. We appreciate the assistance of $D$. Beames, R. Adams, R. Emerson, and the staff of the University of British Columbia Research Farm at Oyster River. We are grateful to D. L. Spittlehouse and M. D. Novak for valuable discussions on the paper.

\section{REFERENCES}

Black, T. A., C. B. Tanner, and W. R. Gardner, Evapotranspiration from a snap bean crop, Agron. J., 62, 66-69, 1970.

Campbell, G. S., Introduction to Environmental Biophysics, SpringerVerlag, New York, 1977.

Denmead, O. T., Plant physiological methods for studying evapotranspiration: Problems of telling the forest from the trees, Agric. Water Manage., 8, 167-189, 1984.

Finnegan, J. J., Turbulent transport in flexible plant canopies, in The Forest-Atmosphere Interaction, edited by B. A. Hutchison and B. B. Hicks, pp. 443-480, D. Reidel, Hingham, Mass., 1985.

Fuchs, M., and C. B. Tanner, Calibration and field test of heat flux plates, Soil Sci. Soc. Am. J., 32, 326-328, 1968.

Garratt, J. R., and B. B. Hicks, Momentum, heat and water vapor transfer to and from natural and artificial surfaces, $Q . J$. R. Meteorol. Soc., 99, 680-687, 1973.

Gates, D. M., Biophysical Ecology, Springer-Verlag, New York, 1980.

Jarvis, P. G., G. B. James, and J. J. Landsberg, Coniferous forest, in Vegetation and the Atmosphere, vol. 2, edited by J. L. Monteith, Pp. 171-240, Academic, Orlando, Fla., 1976.

Kelliher, F. M., Salal understory removal effects on the soil water regime and tree transpiration rates in a Douglas-fir forest, Ph.D. thesis, Univ. of B. C., Vancouver, 1985.

Landsberg, J. J., and D. B. B. Powell, Surface exchange characteristics of leaves subject to mutual interference, Agric. Meteorol., 12, 169$184,1973$.

Lindroth, A., Seasonal variation in pine forest evaporation and canopy conductance, Ph.D. thesis, Univ. of Uppsala, Uppsala, Sweden, 1984.

McNaughton, K. G., and P. G. Jarvis, Predicting effects of vegetation changes on transpiration and evaporation, in Water Deficits and Plant Growth, vol. 7, edited by T. T. Kozlowski, pp. 1-47, AcademIc, Orlando, Fla., 1983.

Monteith, J. L., Evaporation and environment, in The State and Movement of Water in Living Organisms, Symp. Soc. Exp. Biol. No. 19, edited by G. E. Fogg, pp. 205-234, Academic, Orlando, Fla., 1965.

Novak, M. D., and T. A. Black, Theoretical determination of the surface energy balance and thermal regime of bare soils, Boundary Layer Meteorol., 33, 313-333, 1985.

Plamondon, A. P., Hydrologic properties and water balance of the forest floor of a Canadian west coast watershed, Ph.D. thesis, Univ. of B. C., Vancouver, 1972.

Price, D. T., T. A. Black, and F. M. Kelliher, Effects of salal understory removal on photosynthesis rate and stomatal conductance of young Douglas-fir trees, Can. J. For. Res., 16, 90-97, 1986.

Raupach, M. R., and A. S. Thom, Turbulence in and above plant canopies, Ann. Rev. Fluid Mech., 13, 97-129, 1981.

Roberts, J., C. F. Pymar, J. S. Wallace, and R. M. Pitman, Seasonal changes in leaf area, stomatal conductance and transpiration from bracken below a forest canopy, J. Appl. Ecol., 17, 409-422, 1980.

Rutter, A. J., K. A. Kershaw, P. C. Robins, and A. J. Morton, A predictive model of rainfall interception in forests, 1 , Derivation of the model from observations in a plantation of Corsican pine, Agric. Meteorol., 9, 367-384, 1971.

Santantonio, D., R. K. Herman, and W. S. Overton, Root biomass studies in forest ecosystems, Pedobiol., 17, 1-31, 1977.

Shuttleworth, W. J., A simplified one-dimensional theoretical description of the vegetation-atmosphere interaction, Boundary Layer Meteorol., 14, 3-27, 1978.

Shuttleworth, W. J., Below-canopy fluxes in a simplified onedimensional theoretical description of the vegetation-atmosphere interaction, Boundary Layer Meteorol., 17, 315-331, 1979.

Shuttleworth, W. J., and J. S. Wallace, Evaporation from sparse crops-An energy combination theory, Q. J. R. Meteorol. Soc., III, 839-855, 1985.

Spittlehouse, D. L., Measuring and modelling forest evapotranspiration, Ph.D. thesis, Univ. of B. C., Vancouver, 1981.

Spittlehouse, D. L., and T. A. Black, Evaluation of the Bowen ratio/ energy balance method for determining forest evapotranspiration, Atmos. Ocean, 18, 98-116, 1980.

Spittlehouse, D. L., and T. A. Black, A growing season water balance model applied to two Douglas-fir stands, Water Resour. Res., 17 1651-1656, 1981a.

Spittlehouse, D. L., and T. A. Black, A comparison of reversing psychrometric Bowen ratio measurement systems, Atmos. Ocean, 19 , 372-379, $1981 b$.

Spittlehouse, D. L., and T. A. Black, A growing season water balance model used to partition water use between trees and understory, in Proceedings of Canadian Hydrology Symposium 82, Processes in Forested Areas, Fredericton, New Brunswick, Canada, pp. 195-214, Associate Committee on Hydrology, National Research Council, Ottawa, 1982.

Stanhill, G., A simple instrument for the field measurement of turbulent diffusion flux, J. Appl. Meteorol., 8, 509-513, 1969.

Stewart, J. B., Measurement and prediction of evaporation from forested and agricultural catchments, Agric. Water Manage., 8, 1-28, 1984.

Stewart, J. B., and A. S. Thom, Energy budgets in pine forest, $Q . J . R$. Meteorol. Soc., 99, 154-170, 1973.

Szeicz, G., G. Endrodi, and S. Tajchman, Aerodynamic and surface factors in evaporation, Water Resour. Res., 5, 380-394, 1969.

Tan, C. S., and T. A. Black, Factors affecting the canopy resistance of a Douglas-fir forest, Boundary Layer Meteorol., 10, 475-488, 1976.

Tan, C. S., T. A. Black, and J. U. Nnyamah, Characteristics of stomatal diffusion resistance in a Douglas-fir forest exposed to soil water deficits, Can. J. For. Res., 7, 595-604, 1977.

Tan, C. S., T. A. Black, and J. U. Nnyamah, A simple diffusion model of transpiration applied to a thinned Douglas-fir stand, Ecol., 59, 1221-1229, 1978 . 
Thom, A. S., Momentum, mass and heat exchange of vegetation, $Q$. $J$. R. Meteorol. Soc., 98, 124-134, 1972.

Thom, A. S., Momentum, mass and heat exchange of plant communities, in Vegetation and Atmosphere, vol. 1, edited by J. L. Monteith, pp. 57-109, Academic, Orlando, Fla., 1975.

Van Wijk, W. R., and D. A. De Vries, Periodic temperature variation, in Physics of Plant Environment, edited by W. R. Van Wijk, pp. 102-143, North-Holland, Amsterdam, 1963.

T. A. Black, Department of Soil Science, The University of British Columbia, 139, 2357 Main Mall, Vancouver, British Columbia Canada V6T 2A2.
F. M. Kelliher, Forest Research Institute, Private Bag, Rotorua, New Zealand

D. T. Price, Faculty of Forestry, University of British Columbia, Vancouver, British Columbia V6T 1W5.

\author{
(Received February 4, 1986; \\ revised August 5, 1986; \\ accepted August 5, 1986.)
}

